\title{
Promotion of Growth and Yield in Cucumber by Zoysiagrass Rhizosphere Fungi
}

\author{
Manchanahally B Shivanna ${ }^{1}$, Manchanahally S MeERA ${ }^{1}$, Mayumi Kubota ${ }^{2}$ and \\ MITSURO HYAKUMACHI ${ }^{2 *}$ \\ ${ }^{1}$ Department of Applied Botany, Kuvempu University, Shankara Ghatta 577-451, Shimoga Dist, Karnataka, \\ India \\ ${ }^{2}$ Faculty of Applied Biological Sciences, Gifu University, 1-1 Yanagido, Gifu 501-1193, Gifu, Japan
}

(Received June 16, 2004-Accepted November 12, 2004)

Nine fungi belonging to the Phoma sp. and one non-sporulating fungus from zoysiagrass rhizospheres were tested for their ability to promote the growth of cucumber plants (cv. Aodai kyuri, Jibai, Ochiai fushinari, and Shogoin fushinari) at 4 weeks after planting in a growth chamber. The fungal isolates were introduced individually into natural soil in barley kernels $(2 \%, \mathrm{w} / \mathrm{w})$. The result indicated that plant dry biomass rather than plant length was increased by all the fungal isolates and the increase was cultivar-specific. Isolates GS8-1, GS8-2 and GS8-3 which had a consistent growth-promoting effect on both the height and dry biomass of all cultivars and GU21-2, which had less of an effect on growth and yield, were further tested for their ability to promote growth of a popular cv. Jibai until 10 weeks in the greenhouse and field. All isolates significantly increased plant length and plant dry biomass at 6 and 10 weeks after planting, and the number of leaves and cucumbers produced at 10 weeks in the greenhouse. In the field, these isolates were also effective in promoting growth and increasing yield at 6 and 10 weeks. The number and fresh biomass of marketable cucumbers produced at 6 weeks was significantly high in comparison to that of untreated controls. At 10 weeks after planting, the number of marketable cucumbers was significantly increased by isolates GS8-3 and GU21-2, while the fresh biomass of marketable cucumbers was significantly increased by all four isolates. GS8-1, GS8-2 and GS8-3 were isolated from roots of cucumber (cv. Jibai) even at 10 weeks after planting in both the greenhouse and field experiments. GU21-2 was not isolated from cucumber roots. It is suggested that the increased absorption of mineral nutrient by plants following the colonization and degradation of barley kernels by fungal isolates and the association of fungal isolates with roots might lead to enhanced plant growth and increased yield.

Key words: Phoma sp., cucumber, growth promotion, root colonization, field assay

The beneficial effects of certain rhizosphere fungi in terms of plant growth promotion and biological control has been reported by many researchers ${ }^{1-3,7,13,18)}$. Recently, we have also shown that certain fungi identified as Phoma sp. (Sacc.), Penicillium spp. (Link ex Fr.), Fusarium equiseti (Sacc. (Corda)), and Trichoderma spp. (Pers. ex Fr.) as well as other non-sporulating fungi isolated from Zoysiagrass (Zoysia tenuifolia Willd. ex Trin.) rhizospheres promoted the growth of several plants and suppressed some soil-borne

\footnotetext{
* Corresponding author; E-mail: hyakumac@cc.gifu-u.ac.jp, Tel: +81-58-293-2847, Fax: +81-58-293-2847
}

and air-borne diseases ${ }^{4-6,9,10,15)}$. The growth and yield of soybean and wheat due to some of these isolates was also tested $^{14,16)}$.

In this study, we evaluated the growth-promoting effect on cucumber of Phoma isolates and non-sporulating fungal isolates which have been used previously in soybean and wheat ${ }^{16)}$. Four cucumber cultivars were tested to evaluate the growth promotion based on plant height and biomass in a growth chamber. Further evaluation was done both in a greenhouse and in the field based on numbers of leaves, fruits and marketable fruits. Since growth promotion has been already observed in previous studies in greenhouses 
using commercial potting media ${ }^{10-12)}$, natural soil was used as the potting medium throughout these experiments. Root colonization in cucumber by these fungi was also observed in order to discuss the possible roles of colonization in the growth-promoting effect.

\section{Materials and methods}

\section{Isolates, preparation of inoculum and soil used}

The fungal isolates used were Phoma sp. strains GS6-1, GS6-2, GS6-4, GS7-4, GS8-1, GS8-2, GS8-3, GS8-6 and GS10-2 and a non-sporulating fungus, GU21-2. All these fungi were obtained from zoysiagrass rhizospheres. Individual fungal isolates were mass-cultured on autoclaved barley (Hordeum vulgare L.) kernels under axenic conditions ${ }^{14)}$ and the colony forming ability was tested on potato dextrose agar (PDA) before the application to soil. Brown loam ( $\mathrm{pH}$ 6.5) from an agricultural farm, Gifu University, was used throughout the study. The soil contained $0.71 \%$ total carbon, $0.07 \%$ soluble carbon, $1.90 \%$ total nitrogen, $0.05 \%$ total phosphorus $\left(\mathrm{P}_{2} \mathrm{O}_{5}\right), 0.04 \%$ soluble phosphorus $\left(\mathrm{P}_{2} \mathrm{O}_{5}\right)$, and $0.30 \%$ potassium.

\section{Growth chamber experiment}

Four cucumber cultivars: Aodai kyuri, Jibai, Ochiai fushinari and Shogoin fushinari were tested for changes in growth caused by the 10 fungal isolates. A soil mixture consisting of loam and river sand $(1: 1, \mathrm{w} / \mathrm{w})$ was amended separately with the fungal-colonized barley kernels $(2 \%, \mathrm{w} / \mathrm{w})$. As controls, the soil mixture was amended (control 1) or not amended (control 2) with uninfested barley kernels ( $2 \% \mathrm{w} /$ w). A $200 \mathrm{~g}$ amount of soil mixture was taken in a sterilized plastic pot ( $9 \mathrm{~cm}$ diameter $\times 9 \mathrm{~cm}$ height) and sown with two surface disinfected $(0.5 \% \mathrm{NaOCl}$ in water for $2 \mathrm{~min}) \mathrm{cu}-$ cumber seeds. Seven days after germination, one healthy seedling per pot was retained for the study. The growth chamber was maintained at $23 \pm 2{ }^{\circ} \mathrm{C}$ and $80-85 \%$ relative humidity. Plants received natural solar illumination from May to July, 1998. The plants were watered as required and grown for 4 weeks. Pots were arranged in a split-plot design with fungal treatments as the main plot factor and cultivars as the sub-plot factor. The experiment was repeated four times with at least three replicates per treatment.

\section{Greenhouse experiment}

Four fungal isolates, GS8-1, GS8-2, GS8-3 and GU21-2, that promoted plant growth at 4 weeks in the growth chamber were selected. Cucumber cv. Jibai which is commonly cultivated in Japanese greenhouses was selected for the ex- periment. The soil mixture (2500 g per pot) was prepared, infested with barley kernels colonized with a rhizosphere fungus, and taken in plastic pots $(19 \mathrm{~cm}$ diameter $\times 19 \mathrm{~cm}$ height). As controls, the soil mixture was amended (control 1) or not amended (control 2) with uninfested barley kernels as in the first experiment. Pots were arranged in a randomized complete block (RCB) design with three replicates for each treatment. Pots were sown with 6 seeds of cucumber and placed in the greenhouse. The number of seedlings was restricted to four per pot after emergence. Plants were kept under conditions of $22^{\circ} \mathrm{C}$ and $80 \%$ relative humidity from May to June, and $26^{\circ} \mathrm{C}$ and $85 \%$ relative humidity from July to August, 1999 and 2000. The light during May and June was supplemented with a $12 \mathrm{~h}$ light regime by using artificial day-light tubes (cool, florescent, $300 \mu$ Einsteins $\mathrm{m}^{-2}$ $\mathrm{sec}^{-1}$ ). Plants were allowed to grow for 10 weeks. The experiment was repeated three times.

\section{Field experiment}

The field (experimental field, Gifu University, Gifu, Japan) experiment was laid out using the RCB design with three replicates. Each replicate plot $(5 \mathrm{~m} \times 7 \mathrm{~m})$ consisted of six rows (each row $5 \mathrm{~m}$ long, $1 \mathrm{~m}$ apart). Each row represented a treatment. The treatments were amendments using barley kernels infested with 4 selected fungal isolates (GS81, GS8-2, GS8-3 and GU21-2), the amendment of soil with uninfested barley kernels (control 1) and no amendment (control 2). Rows were raised above ground level by $15 \mathrm{~cm}$ to drain excess rain water. Five pits $(15 \mathrm{~cm}$ diameter $\times 20 \mathrm{~cm}$ depth) were made in each row and the soil (ca. $2500 \mathrm{~g}$ ) from each pit was taken out and mixed with the barley kernel inoculum $(2 \%, \mathrm{w} / \mathrm{w})$ of an individual fungal isolate or uninfested barley kernels $(2 \%, w / w)$ and replaced back in the same pit. In each pit, two seeds were sown, and upon germination, one seedling per pit was maintained. Plants experienced a temperature range of $23-32^{\circ} \mathrm{C}$, relative humidity of $75-90 \%$ and rainfall of $25 \mathrm{~cm}$. Plants were trained on stakes for 10 weeks. Experiments were conducted from May to July, 2000 and 2001. Hand weeding was done fortnightly. Fertilizer (Nissan Fukugo, Kansai Nissan Co., Osaka, Japan) was applied, once before seed sowing (30 g placed at the bottom of the pit), and again during the third week (17 $\mathrm{g}$ on the soil surface over the pit). The fertilizer contained $8 \%$ (w/ w) each of nitrogen, phosphorus $\left(\mathrm{P}_{2} \mathrm{O}_{5}\right)$ and potassium $\left(\mathrm{K}_{2} \mathrm{O}\right)$.

\section{Assessment of growth promotion}

The aerial shoots of plants grown in the growth chamber were harvested at 4 weeks after planting, while those of 
plants grown in the greenhouse were harvested at 6 and 10 weeks, and shoot length was measured. The dry biomass of the shoots was measured by drying the shoots at $100^{\circ} \mathrm{C}$ for $24 \mathrm{~h}^{14)}$. In the case of plants grown in the field, the shoot length and the number of leaves produced were determined at 6 and 10 weeks. Fruits were harvested at 6 and 10 weeks, and separated into marketable and culled fruits. Their number and fresh biomass were determined. Fruits graded GifuJapan class A or B were considered marketable: class $\mathrm{A}=>101 \mathrm{~g}$, class $\mathrm{B}=>70 \mathrm{~g}$ to $100 \mathrm{~g}$ or elliptical shape, respectively. Other grades having less than $70 \mathrm{~g}$, an irregular shape, a puffy appearance or cracking were unmarketable.

\section{Colonization ability of fungal isolates}

After separation of the aerial shoots of plants grown in the growth chamber, greenhouse and field, the roots were removed intact from the soil. Roots were washed first in tap water and then in sterile water. The roots were surface disinfected $(2 \% \mathrm{NaOCl}$ in water for $30 \mathrm{~s})$ and cut into 200 $1-\mathrm{cm}$ long segments, aseptically, and incubated on PDA+chloramphenicol or streptomycin $\left(200 \mathrm{mg} \mathrm{l}^{-1}\right)$. The colonies emerging from root segments were identified by comparing their characteristics with those of the original fungal colonies on $\mathrm{PDA}^{12)}$. The isolation frequency (\%) of the fungus was calculated by counting the number of segments yielding fungal colonies from a total of 200 incubated segments per treatment.

\section{Statistical analysis}

The data from the growth chamber experiment were analyzed in a split-plot design with fungal treatment as the main plot factor and cultivar as the sub-plot factor using the analysis of variance (ANOVA) $(P=0.01)$. Significant effects were subjected to orthogonal contrast using Fischer's least significant difference test (LSD, $P=0.05,0.01$ ) and Duncan's multiple range test (DMRT, $P=0.05$ ). The data from the greenhouse and field experiments were also analyzed using the split-plot design with fungal treatment as the main plot factor and growth stage as the sub-plot factor to test if the fungal isolates varied in their ability to cause growth promotion and increase yield at different growing stages. Analysis of the data of trials yielded homogeneity of variance when tested with Bartlett's test and hence replicate data of trials were combined and ANOVA was done. When there were significant $(P=0.05)$ main and interaction effects of growing stage and fungal treatment, mean comparisons were performed with either the LSD test or DMRT.

\section{Results}

\section{Growth chamber experiment}

The ability of these 10 fungal isolates to promote growth in the four cultivars varied. At least five of the isolates caused a significant increase $(P=0.05)$ in plant length in all cultivars in comparison to controls grown in soil supplemented with uninfested barley kernels (control 1) (Table 1). However, all of the isolates selected caused a significant increase $(P=0.05)$ in the dry biomass of the four cultivars in comparison to the untreated control (control 2) (Table 2). Among some cultivars, Aodai kyuri, Jibai and Shogoin fusihari, supplementation of the soil with autoclaved uninfested barley kernels (control 1) also resulted in an increase in either or both plant length and plant dry biomass in comparison to the untreated control (control 2) (Tables 1 and 2).

\section{Greenhouse experiment}

All four fungal isolates caused a significant increase $(P=0.01)$ in growth at 6 and 10 weeks in comparison to the untreated plants (control 2) in the greenhouse (Table 3). These isolates also increased $(P=0.01)$ the number of leaves and fruits produced in comparison to the untreated control. Although the interaction between fungal isolates and growing stage was not significant $(P=0.05)$ for plant length, it was significant $(P=0.01)$ for plant dry biomass. Treatment of soil with uninfested barley kernels (control 1) significantly increased $(P=0.05)$ plant length but did not increase biomass relative to the untreated control (control 2). However, it induced plants to produce more leaves $(P=0.05)$ and fruits $(P=0.01)$ at 10 weeks (Table 3$)$.

\section{Field experiment}

The field experiments yielded similar results to the greenhouse experiments. All four fungal isolates tested increased $(P=0.01)$ plant length at 6 and 10 weeks in comparison to the untreated control (control 2) (Table 4). All the isolates also increased the number of leaves as well as the number of fruits at 6 and 10 weeks. The total biomass of fruits produced rose significantly $(P=0.01)$ due to fungal treatment. The actual increase in yield was reflected by the change in the number and biomass of marketable fruits produced at 6 and 10 weeks. Among the four PGPF isolates, GS8-3 and GU21-1 caused a greater increase $(P=0.01)$ in the biomass of marketable fruits than GS8-1 and GS8-2 at 6 weeks. Although GS8-1 and GS8-2 did not increase the number of marketable fruits at 10 weeks, they increased in biomass of the fruits produced $(P=0.01)$. At 10 weeks, isolate GU21-2 
Table 1. Effect of supplementation of natural soil with barley kernel inocula $(2 \%, w / w)$ of zoysiagrass rhizosphere fungus on the length of 4 week-old plants of cucumber cultivars in the growth chamber ${ }^{\mathrm{a}}$

\begin{tabular}{|c|c|c|c|c|c|c|c|c|}
\hline \multirow{3}{*}{ Treatments } & \multicolumn{8}{|c|}{ Plant length $(\mathrm{cm})$} \\
\hline & \multicolumn{2}{|c|}{ Aodai kyuri } & \multicolumn{2}{|c|}{ Jibai } & \multicolumn{2}{|c|}{ Ochiai fushinari } & \multicolumn{2}{|c|}{ Shogoin fushinari } \\
\hline & Mean & $\mathrm{DMRT}^{\mathrm{b}}$ & Mean & DMRT & Mean & DMRT & Mean & DMRT \\
\hline GS6-1 & 14.2 & $a b$ & 13.4 & $\mathrm{a}$ & 8.2 & $\mathrm{~d}$ & 9.1 & $\mathrm{~d}$ \\
\hline GS6-2 & 11.1 & de & 12.8 & $\mathrm{a}$ & 10.0 & $a b$ & 10.6 & $a b$ \\
\hline GS6-4 & 13.0 & $\mathrm{bc}$ & 9.5 & de & 10.2 & $a b$ & 9.7 & bcd \\
\hline GS7-4 & 12.4 & $\mathrm{~cd}$ & 12.9 & $\mathrm{a}$ & 8.2 & $\mathrm{~d}$ & 8.9 & $\mathrm{~d}$ \\
\hline GS8-1 & 10.0 & ef & 10.0 & $\mathrm{~cd}$ & 11.0 & $\mathrm{a}$ & 9.6 & bed \\
\hline GS8-2 & 11.7 & $\mathrm{~d}$ & 11.0 & $\mathrm{bc}$ & 10.2 & $\mathrm{ab}$ & 10.0 & bcd \\
\hline GS8-3 & 11.2 & de & 12.2 & $a b$ & 9.5 & $\mathrm{bc}$ & 9.4 & $\mathrm{~cd}$ \\
\hline GS8-6 & 11.7 & $\mathrm{~d}$ & 12.6 & $\mathrm{a}$ & 8.9 & $\mathrm{~cd}$ & 10.4 & $\mathrm{~cd}$ \\
\hline GS10-2 & 14.7 & a & 13.2 & $\mathrm{a}$ & 8.1 & $\mathrm{~d}$ & 11.1 & a \\
\hline GU21-2 & 9.5 & $\mathrm{fg}$ & 11.0 & bc & 8.8 & $\mathrm{~cd}$ & 8.9 & d \\
\hline Control $1^{\mathrm{c}}$ & 8.4 & g & 8.5 & ef & 8.2 & $\mathrm{~d}$ & 7.7 & $\mathrm{e}$ \\
\hline Control $2^{\mathrm{d}}$ & 6.7 & $\mathrm{~h}$ & 7.3 & $\mathrm{f}$ & 7.9 & $\mathrm{~d}$ & 7.5 & $\mathrm{e}$ \\
\hline
\end{tabular}

${ }^{a}$ Means of four trials each with three replicates. The experiment was done with a factorial design. There was a significant $(P=0.01)$ effect of fungal treatment $\times$ cucumber cultivar. Means of varieties are compared horizontally. LSDs to compare means at fungal treatments and cucumber cultivars are 1.1 and $1.4(P=0.05,0.01)$.

${ }^{\mathrm{b}}$ Same letters in a column are not significantly different according to Duncan's multiple range test (DMRT) $(P=0.05)$.

${ }^{\mathrm{c}}$ Soil amended with uninfested autoclaved barley kernels $(2 \%, \mathrm{w} / \mathrm{w})$.

${ }^{\mathrm{d}}$ Not amended with barley kernels.

Table 2. Effect of supplementation of natural soil with barley kernel inocula $(2 \%, w / w)$ of zoysiagrass rhizosphere fungus on the dry biomass of 4-week-old plants of cucumber cultivars in the growth chamber ${ }^{\mathrm{a}}$

\begin{tabular}{|c|c|c|c|c|c|c|c|c|}
\hline \multirow{3}{*}{ Treatments } & \multicolumn{8}{|c|}{ Plant dry biomass (mg) } \\
\hline & \multicolumn{2}{|c|}{ Aodai kyuri } & \multicolumn{2}{|c|}{ Jibai } & \multicolumn{2}{|c|}{ Ochiai fushinari } & \multicolumn{2}{|c|}{ Shogoin fushinari } \\
\hline & Mean & DMRT $^{\mathrm{b}}$ & Mean & DMRT & Mean & DMRT & Mean & DMRT \\
\hline GS6-1 & 530 & $\mathrm{~b}$ & 450 & $\mathrm{a}$ & 376 & $\mathrm{f}$ & 600 & $\mathrm{~d}$ \\
\hline GS6-2 & 353 & $\mathrm{f}$ & 302 & g & 439 & $\mathrm{~cd}$ & 709 & $b$ \\
\hline GS6-4 & 511 & $\mathrm{c}$ & 346 & $\mathrm{f}$ & 467 & $a b$ & 478 & $\mathrm{f}$ \\
\hline GS7-4 & 498 & $\mathrm{c}$ & 392 & $\mathrm{c}$ & 443 & cd & 465 & fg \\
\hline GS8-1 & 330 & g & 379 & $\mathrm{~cd}$ & 451 & $\mathrm{bc}$ & 450 & gh \\
\hline GS8-2 & 438 & $\mathrm{e}$ & 361 & def & 483 & $\mathrm{a}$ & 511 & $\mathrm{e}$ \\
\hline GS8-3 & 457 & $d$ & 360 & ef & 427 & $\mathrm{~d}$ & 430 & $\mathrm{i}$ \\
\hline GS8-6 & 453 & $\mathrm{~d}$ & 373 & de & 405 & $\mathrm{e}$ & 655 & $\mathrm{c}$ \\
\hline GS10-2 & 606 & $\mathrm{a}$ & 414 & $\mathrm{~b}$ & 328 & g & 750 & $\mathrm{a}$ \\
\hline GU21-2 & 253 & $\mathrm{~h}$ & 295 & g & 389 & ef & 441 & hi \\
\hline Control $1^{\mathrm{c}}$ & 200 & $\mathrm{i}$ & 263 & $\mathrm{~h}$ & 233 & $\mathrm{~h}$ & 263 & $\mathrm{j}$ \\
\hline Control $2^{d}$ & 158 & $\mathrm{j}$ & 203 & $\mathrm{i}$ & 222 & $\mathrm{~h}$ & 239 & $\mathrm{k}$ \\
\hline
\end{tabular}

${ }^{a}$ Mean of four trials each with three replicates. The experiment was done with a factorial design. There was a significant $(P=0.01)$ effect of fungal treatment $\times$ cucumber cultivar. Means of varieties are compared horizontally. LSDs to compare means at fungal treatments and cucumber cultivars are 14 and $18(P=0.05,0.01)$.

${ }^{\mathrm{b}}$ Same letters in a column are not significantly different according to Duncan's multiple range test (DMRT) $(P=0.05)$.

${ }^{\mathrm{c}}$ Soil amended with uninfested autoclaved barley kernels $(2 \%, \mathrm{w} / \mathrm{w})$

${ }^{\mathrm{d}}$ Not amended with barley kernels. 
Table 3. Effect of supplementation of natural soil with barley kernel inocula $(2 \%, w / w)$ of zoysiagrass rhizosphere fungus on plant length, dry biomass and numbers of leaves and fruits of cucumber cv. Jibai at 6 and 10 weeks in the greenhouse ${ }^{\mathrm{a}}$

\begin{tabular}{|c|c|c|c|c|c|c|}
\hline \multirow{2}{*}{ Treatments } & \multicolumn{2}{|c|}{ Plant length $(\mathrm{cm})$} & \multicolumn{2}{|c|}{ Plant dry biomass (g per plant) } & \multicolumn{2}{|c|}{ Number at 10 weeks (per plant) } \\
\hline & 6 weeks & 10 weeks & 6 weeks & 10 weeks & Leaves & Fruits \\
\hline GS8-1 & $55.8^{* * \mathrm{~b}}$ & $97.7 * *$ & $2.194 * *$ & $3.477 * *$ & $12.0^{* *}$ & $8.7 * *$ \\
\hline GS8-2 & $67.8 * *$ & $104.0^{* *}$ & $2.437^{* *}$ & $3.193 * *$ & $10.3^{* *}$ & $6.3 * *$ \\
\hline GS8-3 & $46.9^{* *}$ & $87.0^{* *}$ & $2.016^{* *}$ & $2.339^{* *}$ & $10.3 * *$ & $5.7 * *$ \\
\hline GU21-2 & $59.6 * *$ & $97.8^{* *}$ & $1.832 * *$ & $2.471^{* *}$ & $11.0^{*}$ & $8.3^{* *}$ \\
\hline Control $1^{\mathrm{c}}$ & $41.1^{*}$ & $79.1^{*}$ & 1.292 & 1.987 & $9.0^{*}$ & $5.3^{* *}$ \\
\hline Control $2^{\mathrm{d}}$ & 36.2 & 73.1 & 1.188 & 1.849 & 7.3 & 3.3 \\
\hline
\end{tabular}

${ }^{a}$ Mean of four trials each with three replicates. Data on plant length and plant dry biomass were analyzed with a randomized complete block design. Means of rhizosphere fungi were compared vertically. The effect of fungal treatment $\times$ growing stage for plant length was not significant $(P=0.05)$, while the interaction for dry biomass was significant. LSDs to compare means of plant dry biomass at two stages in a row are $0.225 \mathrm{~g}$ and $0.361 \mathrm{~g}(P=0.05,0.01)$, respectively.

${ }^{\mathrm{b}}$ Values followed by single and double asterisks in a column are significantly different compared to untreated control (control 2$)$ at LSD, $P=0.05$ and 0.01 , respectively.

${ }^{\mathrm{c}}$ Soil amended with uninfested autoclaved barley kernels $(2 \%, \mathrm{w} / \mathrm{w})$.

${ }^{\mathrm{d}}$ Not amended with barley kernels.

Table 4. Effect of supplementation of soil with barley kernel inocula $(2 \%, w / w)$ of zoysiagrass rhizosphere fungal isolates on plant length, number of leaves and the number and fresh biomass of fruits of cucumber cv. Jibai at 6 and 10 weeks (wk) in the field ${ }^{\mathrm{a}}$

\begin{tabular}{|c|c|c|c|c|c|c|c|c|c|c|c|c|}
\hline \multirow{3}{*}{ Treatments } & \multirow{2}{*}{\multicolumn{2}{|c|}{ Plant length $(\mathrm{cm})$}} & \multirow{2}{*}{\multicolumn{2}{|c|}{$\begin{array}{l}\text { Number of leaves } \\
\text { (per plant) }\end{array}$}} & \multicolumn{4}{|c|}{ Total fruits per plant } & \multicolumn{4}{|c|}{ Marketable fruits per plant } \\
\hline & & & & & \multicolumn{2}{|c|}{ Number } & \multicolumn{2}{|c|}{ Fresh biomass (kg) } & \multicolumn{2}{|c|}{ Number } & \multicolumn{2}{|c|}{ Fresh biomass (kg) } \\
\hline & $6 \mathrm{wk}$ & $10 \mathrm{wk}$ & $6 \mathrm{wk}$ & $10 \mathrm{wk}$ & $6 \mathrm{wk}$ & $10 \mathrm{wk}$ & $6 \mathrm{wk}$ & $10 \mathrm{wk}$ & $6 \mathrm{wk}$ & $10 \mathrm{wk}$ & $6 \mathrm{wk}$ & $10 \mathrm{wk}$ \\
\hline GS8-1 & $65.8^{* * \mathrm{~b}}$ & $122.0^{* *}$ & $9.4 * *$ & $14.3^{* *}$ & $3.8^{* *}$ & 3.4 & $0.392 * *$ & $1.312 * *$ & $1.5^{* *}$ & 2.1 & $0.300^{* *}$ & $1.081^{* *}$ \\
\hline GS8-2 & $75.2^{* *}$ & $119.7^{* *}$ & $10.2 * *$ & $16.2 * *$ & $4.3^{* *}$ & $4.7^{* *}$ & $0.564^{* *}$ & $1.440^{* *}$ & $2.7 * *$ & 2.5 & $0.400^{* *}$ & $1.048^{* *}$ \\
\hline GS8-3 & $64.6^{* *}$ & $109.3^{* *}$ & $9.4 * *$ & $15.4^{* *}$ & $4.0^{* *}$ & $9.4^{* *}$ & $0.304 * *$ & $1.940 * *$ & $2.3 * *$ & $3.5^{* *}$ & $0.480^{* *}$ & $1.068^{* *}$ \\
\hline GU21-2 & $66.6 * *$ & $139.7^{* *}$ & $9.8^{* *}$ & $14.3^{* *}$ & $5.0^{* *}$ & $4.9 * *$ & $0.588^{* *}$ & $1.392 * *$ & $2.4^{* *}$ & $3.8^{* *}$ & $0.540^{* *}$ & $1.224^{* *}$ \\
\hline Control $1^{\mathrm{c}}$ & 43.0 & $114.0^{* *}$ & 7.8 & 12.2 & $3.2^{*}$ & 4.0 & $0.264 * *$ & $1.100^{* *}$ & 0.8 & 2.0 & $0.100^{* *}$ & $0.744^{* *}$ \\
\hline Control $2^{\mathrm{d}}$ & 41.3 & 94.0 & 6.7 & 11.6 & 2.4 & 3.6 & 0.120 & 0.912 & 0.3 & 2.0 & 0.048 & 0.656 \\
\hline
\end{tabular}

${ }^{a}$ Mean of two trials with three replicates. Data analyzed factorially. There was significant interaction $(P=0.01)$. The effect of fungal treatment $\times$ growing stage was significant at $P=0.02$ for number of marketable fruits. LSDs to compare means at two growth stages in a row for plant length are 5.8 and $8.2 \mathrm{~cm}(P=0.05,0.01)$. LSDs to compare means at two growth stages in a row for total number of fruits and number of marketable fruits are 0.7 and $1.0(P=0.05,0.01)$ and 0.6 and $0.8(P=0.05,0.01)$, respectively. LSDs to compare means at two growth stages in a row for fresh biomass of total fruits and marketable fruits are $0.085 \mathrm{~g}$ and $0.121 \mathrm{~g}(P=0.05,0.01)$ and $0.021 \mathrm{~g}$ and $0.030 \mathrm{~g}(P=0.05,0.01)$, respectively. The effect of fungal treatment $\times$ growing stage was not significant $(P=0.05)$ for number of leaves.

${ }^{\mathrm{b}}$ Values followed by single and double asterisks in a column are significantly different compared to untreated control (control 2$)$ at LSD, $P=0.05$ and 0.01 , respectively.

${ }^{\mathrm{c}}$ Soil supplemented with uninfested autoclaved barley kernels $(2 \%, \mathrm{w} / \mathrm{w})$.

${ }^{\mathrm{d}}$ Not amended with barley kernels.

produced the maximal number (3.8) and biomass $(1.224 \mathrm{~kg})$ of marketable fruits. Other isolates were less effective.

Plants grown in soil treated with uninfested barley kernels (control 1) showed increases in the total number of fruits, total fresh biomass of fruits, and fresh biomass of marketable fruits in comparison to the untreated control (control 2), however, the increase was significantly less than that caused by PGPF treatments.

\section{Root colonization ability of rhizosphere fungal isolates}

Isolate GS8-3 followed by GS8-1 were good colonizers of 4-week-old cucumber plants grown in soil supplemented with fungal-colonized barley kernels (Table 5). Isolate GS82 was a weak colonizer of roots and isolate GU21-2 failed to colonize roots. Similar results were obtained in roots of plants grown for 6 weeks in the greenhouse and field. GS8- 
Table 5. Isolation frequency (\%) of zoysiagrass rhizosphere fungus from roots of cucumber cv. Jibai plants grown in natural soil with barley kernel inoculum $(2 \%, w / w)$ of zoysiagrass rhizosphere fungus in the growth chamber, greenhouse and field ${ }^{\mathrm{a}}$

\begin{tabular}{|c|c|c|c|c|c|c|c|c|c|c|}
\hline \multirow{3}{*}{$\begin{array}{c}\text { Zoysiagrass } \\
\text { rhizosphere } \\
\text { isolates }\end{array}$} & \multirow{2}{*}{\multicolumn{2}{|c|}{$\begin{array}{c}\text { Growth chamber } \\
4 \text { weeks }\end{array}$}} & \multicolumn{4}{|c|}{ Greenhouse } & \multicolumn{4}{|c|}{ Field } \\
\hline & & & \multicolumn{2}{|c|}{6 weeks } & \multicolumn{2}{|c|}{10 weeks } & \multicolumn{2}{|c|}{6 weeks } & \multicolumn{2}{|c|}{10 weeks } \\
\hline & Mean & DMRT $^{b}$ & Mean & DMRT & Mean & DMRT & Mean & DMRT & Mean & DMRT \\
\hline GS8-1 & 40.0 & $b$ & 63.5 & $\mathrm{~b}$ & 48.9 & $b$ & 43.5 & $\mathrm{~b}$ & 25.4 & $b$ \\
\hline GS8-2 & 15.7 & $\mathrm{c}$ & 25.2 & $\mathrm{c}$ & 31.6 & $\mathrm{c}$ & 15.6 & $\mathrm{c}$ & 23.7 & $\mathrm{~b}$ \\
\hline GS8-3 & 70.0 & $\mathrm{a}$ & 65.9 & $\mathrm{a}$ & 66.3 & $\mathrm{a}$ & 48.0 & $\mathrm{a}$ & 46.4 & $\mathrm{a}$ \\
\hline GU21-2 & 0.0 & $\mathrm{~d}$ & 0.0 & $\mathrm{~d}$ & 0.0 & d & 0.0 & d & 0.0 & $\mathrm{c}$ \\
\hline
\end{tabular}

${ }^{a}$ Mean of two trials, each with three replicates. Data on root colonization in the greenhouse and field were analyzed using split-plot design, while that from the growth chamber was analyzed with a randomized complete block design at 4 weeks as a sole variable factor. The effect of fungal treatment $\times$ growing stage for isolation frequency was significant $(\mathrm{P}<0.01)$. Means of isolation frequency of rhizosphere fungi at two stages in the greenhouse and field were compared. LSDs to compare means at two growth stages in a row for greenhouse are 3.1 and $4.5 \%(P=0.05,0.01)$. LSDs to compare means at two growth stages in a row for field are 3.0 and $4.3 \%(P=0.05,0.01)$.

${ }^{\mathrm{b}}$ Same letters in a column are not significantly different according to Duncan's multiple range test (DMRT) $(P=0.05)$.

3 was isolated in high frequency at both 6 and 10 weeks. GS8-1 was isolated in high frequency at 6 weeks, but significantly low frequency at 10 weeks. On the other hand, GS82 was isolated in low frequency at 6 weeks, but significantly high frequency at 10 weeks (Table 5).

\section{Discussion}

Results of the present study indicated that fungal isolates from zoysiagrass rhizosphere are capable of promoting plant growth and increasing the yield of cucumber plants in controlled and greenhouse conditions as well as in the field.

Although certain isolates failed to induce a significant and consistent plant growth increase, they did not cause stunted growth or disease in 4-week-old plants. The increase in plant length due to PGPF at 4 weeks was not considerable in all the cultivars tested, although the biomass increase was significant compared to untreated controls (Tables 1 and 2). This might suggest that the measurement of plant dry biomass than plant length at 4 weeks would reveal the effect on plant growth. PGPF isolates also caused cultivar-specific growth promotion (Table 2). Previously, we demonstrated that most of the isolates tested in the present study caused a significant increase in the growth of wheat in the greenhouse as well as in the field (M B Shivanna, unpublished data) in contrast to a few isolates that promoted growth in soybean ${ }^{17}$. The variation in the behavior of PGPF isolates in different crops could be attributed to their crop specificity. Many fungal isolates of zoysiagrass rhizosphere have also been found to increase the growth of bentgrass $^{5)}$ and corn (Zea mays L.) ${ }^{17)}$. This might suggest that large numbers of fungi isolated from zoysiagrass rhizo- sphere belonging to Phoma sp. and certain non-sporulating isolates have a greater ability to promote growth in monocot plants than dicot plants. This was further supported by the finding that only a few isolates could colonize roots of cucumber, as made in the present study (Table 5), as compared to a large number of isolates that could colonize roots of wheat and corn ${ }^{17)}$, and bentgrass and zoysiagrass (Hayakawa, unpublished data). However, the ability of isolate GU21-2, which failed to colonize cucumber roots, to increase yield is not understood. Dewan and Sivasithamparam ${ }^{2)}$ observed that a sterile red fungus isolated from rhizospheres of ryegrass (Lolium rigidum L.) and wheat enhanced growth of cereal crops much better than non-cereal crops.

The decreased ability of plants to grow and produce fruits in untreated rows in the field could be due to the low availability of mineral nutrients of soil despite the application of a fertilizer. On the other hand, plants which were associated with PGPF isolates grew better and produced more marketable fruits (Table 4). This could be due to the improvement of soil nutrient conditions by PGPF isolates and the ability of plant roots to derive available mineral nutrients from the soil. Cucumber plants associated with certain PGPF isolates accumulated more inorganic minerals like $\mathrm{Ca}, \mathrm{Mg}$, and $\mathrm{K}$ in the aerial shoot than plants not associated with PGPF isolates $^{8)}$. This suggested that PGPF isolates make available minerals in a readily absorbable form to roots. The availability of mineral nutrients to roots could have been also made possible by the mineralization of barley kernels by PGPF isolates during their colonization of the kernels. Certain isolates of Phoma sp. also increase the ammonia-nitrogen content of barley kernels upon colonization and this in- 
creased availability of ammonium-nitrogen to roots might promote growth since it is easily absorbed by roots ${ }^{14)}$.

Isolate GU21-2 was less effective in promoting plant growth at earlier stages of growth, particularly at 4 weeks (Table 1). At 6 and 10 weeks, however, GU21-1 significantly enhanced the growth of cucumber (Tables 3 and 4). This isolate also increased the yield of marketable fruits (Table 4). The ability of GU21-2 to increase yield without colonizing roots is not well understood. However, a prolonged association of certain PGPF isolates with the plants' roots might induce beneficial effects in terms of increase in yield. Along with the enhanced mineral nutrient situation in soil due to PGPF treatment, mycelial exudation seemed to also play an important role in growth promotion. Meera et al. ${ }^{10)}$ showed that the treatment of cucumber seeds with mycelial inocula or culture filtrate of certain PGPF isolates enhanced the growth of cucumber plants. Further, methanol extracts from a mycelial inoculum and culture filtrate were found to have growth-promoting effects in cucumber seedlings (M B Shivanna, unpublished data).

The treatment of soil with uninfested barley kernels resulted in a slight increase in growth and yield (Tables 3 and 4). This increase could be due to the mineralization of barley kernels by beneficial saprophytic microorganisms that might be present in the soil. However, the increase in growth and yield associated with uninfested barley kernels is not comparable to that caused by the PGPF isolates used in the present study. This is further supported by the fact that plant growth is only marginally promoted when uninfested barley kernels are applied to sterilized soil ${ }^{4,14,17)}$.

Results of the present investigation suggest that zoysiagrass rhizosphere fungi could be used to enhance plant growth and increase cucumber yield. Further work is needed to determine whether PGPF isolates induce growth promotion in various types of soil differing in texture, $\mathrm{pH}$, nutrient conditions, and microbial population. Besides the role of these fungi as PGPF, their beneficial role as biological control agents and as inducers of systemic resistance in plants $^{5,6,9,10)}$ has potential implications for introducing PGPF into agricultural soil.

\section{Acknowledgement}

The senior author acknowledges the Monbukagakusho scholarship funded by the Ministry of Education, Science, Sports and Culture, Japan.

\section{References}

1) Baker, R. 1991. Induction of rhizosphere competence in biological fungus Trichoderma, p. 221-228. In D.L. Keister and P.B. Cregan (ed.), The Rhizosphere and Plant Growth. Kluwer Academic publishers, Dordrecht, The Netherlands.

2) Dewan, M.M. and K. Sivasithamparam. 1989. Growth promotion of rotation crop species by a sterile fungus from wheat and the effect of soil temperature and moisture on its suppression of take all. Mycol. Res. 93: 156-160.

3) Hall, G. 1987. SEM studies of sterile fungi on roots of sterile wheat seedlings. Trans. Br. Mycol. Soc. 88: 549-553.

4) Hyakumachi, M. 1994. Plant growth promoting fungi from turfgrass rhizosphere with potentials for disease suppression. Soil Microorganisms 44: 53-68.

5) Hyakumachi, M. 1997. Induced systemic resistance against anthracnose in cucumber due to plant growth-promoting fungi and studies on mechanisms, p. 164-169. In A. Ogoshi, K. Kobayashi, Y. Homma, F. Kodama, N. Kondo and S. Akino (ed.), Fourth International Workshop on Plant Growth Promoting Rhizobacteria. Nakanishi Printing, Sapporo, Japan.

6) Hyakumachi, M. and M. Kubota. 2003. Fungi as plant growth promoter and disease suppressor, p. 101-110. In Arora D.K. (ed.), Agriculture, Food and Environmental Biotechnology Applications. Marcel Dekker, Inc., USA.

7) Kleifeld, O. and I. Chet. 1992. Trichoderma harzianum -interaction with plants and effect on growth response. Plant Soil 144: 267-272.

8) Kohara, E., K. Kageyama and M. Hyakumachi. 1993. Investigation on the plant growth enhancing mechanism by plant growth promoting fungi. Ann. Phytopathol. Soc. Jpn. 59: 73.

9) Koike, N., M. Hyakumachi, K. Kageyama, S. Tsuyumu and N. Doke. 2001. Induction of systemic resistance in cucumber against several diseases by plant growth-promoting fungi: lignification and superoxide generation. Eur. J. Plant Pathol. 107: 523-533.

10) Meera, M.S., M.B. Shivanna, K. Kageyama and M. Hyakumachi. 1994. Plant growth promoting fungi from zoysiagrass rhizosphere as potential inducers of systemic resistance in cucumber. Phytopathology 84: 1399-1406.

11) Meera, M.S., M.B. Shivanna, K. Kageyama and M. Hyakumachi. 1995. Responses of cucumber cultivars to induction of systemic resistance against anthracnose by plant growth promoting fungal isolates. Eur. J. Plant Pathol. 101: 421-430.

12) Meera, M.S., M.B. Shivanna, K. Kageyama and M. Hyakumachi. 1995. Persistence of induced systemic resistance in cucumber in relation to root colonization by plant growth promoting fungal isolates. Crop Prot. 14: 123-130.

13) Narita, Y. and T. Suzui. 1991. Influence of a sterile dark, mycelial fungus on take-all of wheat. Annal. Phytopath. Soc. Jpn. 57: 301-305.

14) Shivanna, M.B., M.S. Meera and M. Hyakumachi. 1994. Sterile fungi from zoysiagrass rhizosphere as plant growth promoters in spring wheat. Can. J. Microbiol. 40: 637-644.

15) Shivanna, M.B., M.S, Meera and M. Hyakumachi. 1996. Role of root colonization ability of plant growth promoting fungi in the suppression of take-all and common root rot of wheat. Crop Prot. 15: 497-504.

16) Shivanna, M.B., M.S, Meera, K. Kageyama and M. Hyakumachi. 1996. Growth promotion ability of zoysiagrass rhizosphere fungi in consecutive plantings of wheat and soybean. Mycoscience 37: $163-168$

17) Shivanna, M.B., M.S. Meera, K. Kageyama and M. Hyakumachi. 1995. Influence of zoysiagrass rhizosphere fungal isolates on growth and yield of soybean plants. Mycoscience 36: 25-30.

18) Windham, M.T., Y. Elad and R. Baker. 1986. A mechanism for increased plant growth induced by Trichoderma spp. Phytopathology 76: 518-521. 